\title{
PENURUNAN PELAYANAN JALAN AKIBAT DISINTEGRATION, UTILITY CUT DEPRESSION, BLEEDING, DAN POLISHED AGGREGATE PADA PERKERASAN LENTUR
}

\author{
M. Fauzan (), Herman Fithra ${ }^{2)}$, Said Jalalul Akbar ${ }^{3)}$, M.Kabir Ihsan ${ }^{4)}$ \\ Jurusan Teknik Sipil, Universitas Malikussaleh
}

\begin{abstract}
Abstrak
Umur pelayanan jalan sangat ditentukan oleh kondisi permukaan perkerasan didasari pada profil permukaan yang diukur dengan hasil indek permukaannya. Indek permukaan diperkenalkan oleh AASHTO berdasarkan pengamatan kondisi perkerasan berupa retakan, distorsi, cacat permukaan, lubang dan tambalan. Konstruksi jalan yang rata, kuat dan terpelihara akan memberikan manfaat yang sangat besar bagi transportasi dan perkembangan ekonomi. Tujuan penelitian untuk mengetahui penurunan pelayanan jalan akibat cacat permukaan, penurunan pada bekas penanaman utilitas, kegemukan dan pengausan di jalan dengan menggunakan metode indek kondisi perkerasan. Penelitian berdasarkan kerusakan disintegration, utility cut depression, bleeding dan polished aggregate. Total nilai indek dari kerusakan-kerusakan akan dikurangi 100\% yang berati sisa pelayanan jalan. Asumsi tingkat kerusakan setiap jenis kerusakan adalah berat. Menggunakan kurva yang disiapkan PCI dapat diketahui besarnya penurunan indek permukaan. Kerusakan jenis disintegration yang berupa stripping dengan luas kerusakan 30\%, 60\% dan 90\% menghasilkan nilai PCI berturut-turut sebesar 91,89 , dan 85, ravelling dengan luas kerusakan 30\%, 60\% dan $90 \%$ menghasilkan nilai PCI berturut-turut sebesar 91, 89, dan 85, serta potholes dengan luas kerusakan 30\%,60\% dan 90\% menghasilkan nilai PCI berturutturut sebesar 85, 78, dan 75. Kerusakan jenis utility cut depression dengan luas kerusakan 30\%, 60\% dan 90\% menghasilkan nilai PCI berturut-turut sebesar 84, 83, dan 82. Kerusakan jenis bleeding dengan luas kerusakan 30\%, $60 \%$ dan 90\% menghasilkan nilai PCI berturut-turut sebesar 98, 96, dan 84 . Kerusakan jenis polished aggregate dengan luas kerusakan 30\%, 60\% dan 90\% menghasilkan nilai PCI berturut-turut sebesar 99, 98, dan 97.
\end{abstract}

Kata-kata kunci: Pelayanan, Kondisi Permukaan Jalan

\section{Pendahuluan}

Perkerasan lentur yang menerima beban dari kendaraan bermotor khususnya kendaraan berat secara berulang-ulang akan menurunkan pelayanan jalan yang ditandai dengan penurunan tekstur pemukaan konstruksi perkerasan. Penurunan tekstur permukaan akan terjadi selama masa pelayanan konstruksi jalan secara perlahan-lahan sesuai dengan umur rencana atau dapat turun dengan cepat akibat kegagalan konstruksi atau penyebab lainnya. Penurunan pelayanan konstruksi jalan salah satunya ditentukan berdasarkan Pavement Condition Index (PCI). Umur rencana adalah umur pelayanan konstruksi perkerasan yang ditetapkan oleh perencanaan saat mendesain konstruksi perkerasan supaya konstruksi tersebut mampu melayani beban lalulintas sesuai dengan spesifikasi yang telah ditentukan. Cacat permukaan (disintegration) pada perkerasan lentur meliputi pengelupasan lapisan permukaan (stripping), pelepasan butir (ravelling), lubang (potholes) dapat terjadi akibat permukaan perkerasan yang secara terus menerus bersentuhan dengan ban kendaraan, proses kimiawi berupa hilangnya aspal akibat oksidasi, dan proses pelaksanaan konstruksi yang tidak benar. Lubang-lubang yang ada 
pada perkerasan diawali dari retakan-retakan kecil yang lama kelamaan menjadi berlubang akibat dari terus dibebani oleh kendaraan dan genangan air hujan, tanpa adanya upaya perbaikan atau perawatan pada saat masih berupa retakan-retakan. Penurunan pada bekas penanaman utilitas (utility cut depression) yang disebabkan karena tidak adanya tanggungjawab pelaksana yang melakukan galian dan penimbunan kembali disepanjang tepi perkerasan. Timbunan kembali dilakukan tanpa prosedur yang benar, dimana seharusnya dilakukan pemadatan lapis demi lapis. Kegemukan (bleeding) terbenamnya agregat dalam aspal disebabkan terlalu banyaknya persentase aspal dalam campuran yang mengakibatkan jalan menjadi licin dan meningkatnya potensi terjadi alur pada perkerasan. Pengausan (polished aggregate) berupa hilangnya aspal pada lapisan permukaan konstruksi perkerasan sedangkan agregat masih utuh yang disebabkan oleh proses oksidasi. Penelitian ini dilakukan untuk mengetahui sisa pelayanan jalan akibat dari disintegration, utility cut depression, bleeding dan polished aggregate dengan menggunakan metode Pavement Condition Index (PCI) sehingga diketahui sisa pelayanan suatu ruas jalan.

\section{Tinjauan Kepustakaan}

\subsection{Lapisan Perkerasan Lentur}

Asphalt Institute MS-5(2001) menyatakan lapisan perkerasan lentur adalah konstruksi yang berada diatas tanah dasar dimana lapisan agregat alam dan bahan pengisi bersama-sama dengan aspal keras menyokong konstruksi sedemikian rupa. Material untuk lapisan perkerasan lentur terdiri dari aspal sebagai perekat, batu pecah, bahan pengisi (filler) atau kerikil.

\subsection{Jenis-jenis Kerusakan}

Jenis-jenis kerusakan pada permukaan perkerasan lentur dapat dibedakan sebagai berikut:

a. Cacat permukaan (disintegration) didasarkan pada kerusakan yang terjadi.

- Lubang (potholes): Lubang terlihat secara jelas berupa mangkuk yang berada pada lapisan permukaan dan bisa sampai lapisan pondasi. Lubang dapat dikategorikan rendah bila diameter lubang $<10 \mathrm{~cm}$ dan kedalaman $<5$ $\mathrm{cm}$, kategori sedang diameter lubang 10-20 cm dan kedalaman $<5 \mathrm{~cm}$, dan kategori berat memiliki diameter lubang $>20 \mathrm{~cm}$ dan kedalaman lubang $>5$ $\mathrm{cm}$. Lubang diukur dalam satuan meter kubik.

- Pelepasan butir (ravelling): Kerusakan ringan adalah kumpulan atau pengikat sudah mulai hilang, kerusakan tingkat menengah adalah kumpulan pengikat sudah mulai hilang, menyebabkan beberapa potensi Freign Object Damage (FOD) permukaan tekstur kasar bintik-bintik dan kerusakan berat adalah kumpulan pengikat sudah hilang, menyebabkan suatu ketinggian potensi FOD permukaan tekstur sangat kasar dan bintik-bintik. Terurai dan pelapukan diukur dalam satuan bujur sangkar (meter kuadrat) atau luas permukaan perkerasan lentur. Kerusakan mekanik disebabkan oleh sangkutan menyeret atau ban melingkari permukaan lentur.

- Pengelupasan lapisan permukaan (stripping): Pengelupasan lapisan permukaan adalah hilangnya agregat pada lapisan permukaan konstruksi perkerasan sedangkan aspal masih utuh. Kerusakan ringan dinyatakan dengan kehilangan agregat $<25 \%$ dari luas area yang ditinjau, kerusakan 
sedang jika kehilangan agregat 25\%-50\% dari luas area yang ditinjau, dan kerusakan berat adalah kehilangan agregat $>50 \%$ dari luas area yang ditinjau. Pengelupasan lapisan permukaan diukur dalam satuan meter kuadrat.

b. Pengausan (polished agregat)

Pengelupasan lapisan permukaan adalah hilangnya aspal pada lapisan permukaan konstruksi perkerasan sedangkan agregat masih utuh. Kerusakan ringan dinyatakan dengan kehilangan aspal $<5 \%$ dari luas area yang ditinjau, kerusakan sedang jika kehilangan aspal 5\%-10\% dan kerusakan berat adalah kehilangan aspal $>10 \%$. Pengausan diukur di dalam satuan meter kuadrat.

c. Kegemukan (bleeding or flushing)

Kegemukan adalah terbenamnya agregat dalam aspal disebabkan terlalu banyaknya persentase aspal dalam campuran. Kategori ringan bila agregat yang terbenam dalam aspal sebesar $<5 \%$ dari luas area yang ditinjau, bila agregat yang terbenam dalam aspal sebesar 5\%-10\% dari luas area yang ditinjau, dan bila agregat yang terbenan dalam aspal sebesar $>10 \%$ dari luas area yang ditinjau. Kegemukan diukur di dalam satuan meter kuadrat.

d. Penurunan pada bekas penanaman utilitas (utility cut depression)

Penurunan konstruksi perkerasan terjadi disepanjang bekas penanaman utilitas, yang terjadi akibat tidak dilakukannya penanaman kembali dengan pemadatan yang benar. Penurunan pada bekas penanaman utilitas ini tidak memiliki tingkatan cukup hanya dengan indikasi sudah terjadi penurunan pada bekas penanaman utilitas. Penurunan pada bekas penanaman utilitas diukur di dalam satuan meter.

\subsection{Tingkat kerusakan (Severity Level)}

U.S. Departement of Transportation (1982) membagi tingkat kerusakan pada perkerasan lentur dalam 3 (tiga) tingkat, yaitu ringan (low), sedang (medium), dan berat (high). Penggolongan tingkat kerusakan tersebut berdasarkan pada masing-masing kerusakan. Tingkat kerusakan ini diukur dalam satuan meter, meter persegi dan meter kubik. Dalam menentukan tingkat kerusakan ini harus dilakukan dengan cermat agar analisis mengenai indek permukaan sesuai dengan kondisi aktual yang ada pada jalan tersebut.

\subsection{Indeks Permukaan}

U.S. Department of Transportation (1982) menyebutkan Pavement Condition Index (PCI) bertujuan untuk operational dan perawatan landasan pacu atau jalan-jalan utama. Teknik pemeliharaan yang berkelanjutan dengan pemecahan masalah retakan perkerasan dan kondisi memburuk. Untuk membantu para pihak mengambil langkah pencegahan dan perbaikan, menyiapkan informasi pada bermacam jenis retakan perkerasan bersamaan dengan rekomendasi aksi untuk perbaikan. Itu juga sebagai petunjuk untuk pemeriksaan perawatan pencegahan dini. U.S. Department of Transportation (1982) membagi Indek Permukaan Perkerasan dalam 7 (tujuh) kelas dengan skala nilai 0 sampai dengan 100. Indeks Kondisi Permukaan dengan skala nilai 85 sampai dengan 100 memperlihatkan kondisi permukaan sama seperti pada saat pengoperasian, skala nilai 70-85 kondisi permukaan sangat baik, skala nilai 55-70 kondisi permukaan 
baik, skala nilai 40-55 kondisi permukaan umumnya masih stabil, dan skala 0-40 kondisi permukaan jelek seperti gambar 2.1 berikut ini.

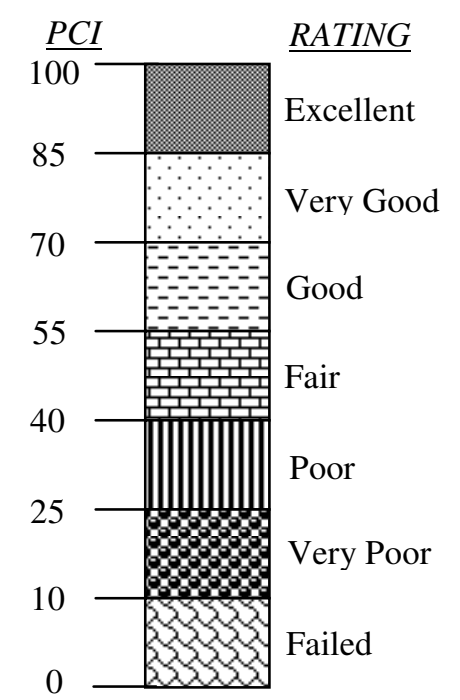

\section{Gambar 2.1. Indeks Kondisi Permukaan Berdasarkan PCI Sumber : U.S. Department of Transportation (1982)}

\section{Metode Penelitian}

\subsection{Tahapan Penelitian}

Tahapan pertama adalah menentukan jenis kerusakan yang terdiri dari disintegration, utility cut depression, bleeding dan polished aggregate dengan skenario kerusakan perkerasan lentur keseluruhannya dalam kondisi berat dengan persentase kerusakan 30\%, 60\% dan 90\% dari total luas kerusakan. Tahapan kedua dengan menggunakan bantuan kurva, nilai mutlak dan persamaan yang berhubungan dengan PCI. dimulai dengan menghitung kadar kerusakan (density), nilai pengurangan (deduct value), total deduct value (TDV) berdasarkan kurva dan nilai mutlak dari PCI, corrected deduct value (CDV), klasifikasi kualitas perkerasan. Terakhir berdasarkan total total deduct value dilakukan pembetulan pengurangan dari kurva dan nilai mutlak dari PCI dan diperoleh klasifikasi kualitas perkerasan. Dari klasifikasi kualitas perkerasan akan dapat ditentukan sisa perkerasan jalan tersebut dengan menguranginya dari nilai seratus persen, dan penentuan rating dari setiap jenis kerusakan dan persentase kerusakannya.

\subsection{Pengolahan Data}

Hasil dari setiap jenis kerusakan dengan tingkatan kerusakan berat pada perkerasan lentur selanjutnya dianalisis dengan menggunakan metode PCI yang disertai dengan kurva-kurva pengurangan.

\section{A. Density (Kadar Kerusakan)}

Density atau kadar kerusakan adalah perbandingan luas volume kerusakan dengan volume ruas yang telah ditentukan sebelumnya diukur dalam meter persegi atau meter panjang dalam satuan persen. Nilai density suatu jenis kerusakan dibedakan juga berdasarkan tingkat kerusakannya dengan persamaan sebagai berikut. 


$$
d=\frac{A}{A_{t o t}} \times 100 \%
$$

dimana:

$$
\begin{aligned}
& d=\text { density } \\
& A=\text { luas ruas rusak } \\
& A_{\text {tot }}=\text { luas sampel unit }
\end{aligned}
$$

\section{B. Deduct Value (Nilai Pengurangan)}

Deduct value adalah nilai pengurangan untuk tiap jenis kerusakan yang diperoleh dari kurva hubungan antara density dan deduct value. Deduct value juga dibedakan atas tingkat kerusakan untuk tiap-tiap jenis kerusakan.

\section{Total Deduct Value (TDV)}

Total Deduct Value adalah nilai total dari individual deduct value untuk tiap jenis kerusakan dan tingkat kerusakan yang ada pada suatu unit penelitian.

\section{Corrected Deduct Value (CDV)}

Corect Deduct Value diperoleh dari kurva hubungan antara nilai TDV dengan CDV dengan pemilihan lengkung kurva sesuai dengan jumlah nilai individual deduct value yang mempunyai nilai lebih besar dari 3. Jika nilai CDV telah diketahui, maka nilai PCI untuk tiap unit dapat diketahui dengan rumus:

$$
P C I(s)=100-C D V
$$

dimana:

PCI (s) = Pavement Condition Index untuk tiap unit.

$\mathrm{CDV}=$ Corrected Deduct Value untuk tiap unit.

untuk nilai PCI secara keseluruhan adalah:

$$
P C I=\frac{\sum P C I(s)}{N}
$$

dimana:

$P C I=$ Nilai PCI perkerasan keseluruhan

$\mathrm{PCI}(\mathrm{s})=$ Nilai PCI untuk tiap unit

$\mathrm{N} \quad=$ Jumlah unit

\section{E. Klasifikasi Kualitas Perkerasan}

Dari nilai (PCI) untuk masing-masing unit penelitian dapat diketahui kualitas lapis perkerasan unit segmen berdasarkan kondisi tertentu yaitu excellent (sempurna), very good (sangat baik), good (baik), fair (sedang), poor (jelek), very poor (sangat jelek), dan failed (gagal).

\section{Hasil dan Pembahasan}

\subsection{Hasil Penelitian}

Hasil pengujian untuk melihat pengaruh disintegration meliputi stripping, ravelling, dan potholes terhadap tingkat pelayanan jalan berdasarkan Pavement Condition Index (PCI) pada perkerasan lentur diperlihatkan Tabel 4.1. sampai 
dengan Tabel 4.3. Tingkat kerusakan perkerasan adalah berat dengan persentase kerusakan $30 \%, 60 \%$, dan $90 \%$ dari luas perkerasan.

Tabel 4.1. Hasil Pemeriksaan Stripping

\begin{tabular}{|c|c|c|c|}
\hline No & $\begin{array}{c}\text { Luas Kerusakan } \\
(\%)\end{array}$ & $\begin{array}{c}\text { Pavement Condition Index } \\
(\mathrm{PCI})\end{array}$ & Keterangan \\
\hline 1 & $30 \%$ & 91 & excellent \\
\hline 2 & $60 \%$ & 89 & excellent \\
\hline 3 & $90 \%$ & 85 & excellent \\
\hline
\end{tabular}

Tabel 4.2. Hasil Pemeriksaan Ravelling

\begin{tabular}{|c|c|c|c|}
\hline No & $\begin{array}{c}\text { Luas Kerusakan } \\
(\%)\end{array}$ & $\begin{array}{c}\text { Pavement Condition Index } \\
(\mathrm{PCI})\end{array}$ & Keterangan \\
\hline 1 & $30 \%$ & 91 & excellent \\
\hline 2 & $60 \%$ & 89 & excellent \\
\hline 3 & $90 \%$ & 85 & excellent \\
\hline
\end{tabular}

Tabel 4.3. Hasil Pemeriksaan Potholes

\begin{tabular}{|c|c|c|c|}
\hline No & $\begin{array}{c}\text { Luas Kerusakan } \\
(\%)\end{array}$ & $\begin{array}{c}\text { Pavement Condition Index } \\
(\mathrm{PCI})\end{array}$ & Keterangan \\
\hline 1 & $30 \%$ & 85 & excellent \\
\hline 2 & $60 \%$ & 78 & very good \\
\hline 3 & $90 \%$ & 75 & very good \\
\hline
\end{tabular}

Hasil pengujian untuk melihat pengaruh utility cut depression terhadap tingkat pelayanan jalan berdasarkan Pavement Condition Index (PCI) pada perkerasan lentur diperlihatkan Tabel 4.3. Tingkat kerusakan perkerasan adalah berat dengan persentase kerusakan 30\%, 60\%, dan 90\% dari luas perkerasan.

Tabel 4.4. Hasil Pemeriksaan Utility Cut Depression

\begin{tabular}{|c|c|c|c|}
\hline No & $\begin{array}{c}\text { Luas Kerusakan } \\
(\%)\end{array}$ & $\begin{array}{c}\text { Pavement Condition Index } \\
(\mathrm{PCI})\end{array}$ & Keterangan \\
\hline 1 & $30 \%$ & 84 & very good \\
\hline 2 & $60 \%$ & 83 & very good \\
\hline 3 & $90 \%$ & 82 & very good \\
\hline
\end{tabular}

Hasil pengujian untuk melihat pengaruh bleeding terhadap tingkat pelayanan jalan berdasarkan Pavement Condition Index (PCI) pada perkerasan lentur diperlihatkan Tabel 4.5. Tingkat kerusakan perkerasan adalah berat dengan persentase kerusakan 30\%, 60\%, dan 90\% dari luas perkerasan.

Tabel 4.5. Hasil Pemeriksaan Bleeding

\begin{tabular}{|c|c|c|c|}
\hline No & $\begin{array}{c}\text { Luas Kerusakan } \\
(\%)\end{array}$ & $\begin{array}{c}\text { Pavement Condition Index } \\
(\mathrm{PCI})\end{array}$ & Keterangan \\
\hline 1 & $30 \%$ & 98 & excellent \\
\hline 2 & $60 \%$ & 96 & excellent \\
\hline 3 & $90 \%$ & 94 & excellent \\
\hline
\end{tabular}

Hasil pengujian untuk melihat pengaruh polished aggregate terhadap tingkat pelayanan jalan berdasarkan Pavement Condition Index (PCI) pada 
perkerasan lentur diperlihatkan Tabel 4.6. Tingkat kerusakan perkerasan adalah berat dengan persentase kerusakan 30\%,60\%, dan 90\% dari luas perkerasan.

Tabel 4.6. Hasil Pemeriksaan Polished Aggregate

\begin{tabular}{|c|c|c|c|}
\hline No & $\begin{array}{c}\text { Luas Kerusakan } \\
(\%)\end{array}$ & $\begin{array}{c}\text { Pavement Condition Index } \\
(\mathrm{PCI})\end{array}$ & Keterangan \\
\hline 1 & $30 \%$ & 99 & excellent \\
\hline 2 & $60 \%$ & 98 & excellent \\
\hline 3 & $90 \%$ & 97 & excellent \\
\hline
\end{tabular}

\subsubsection{Rekapitulasi Hasil Pemeriksaan Berdasarkan Persentase Luas}

Hasil pemeriksaan terhadap disintegration, utility cut depression, bleeding, dan polished aggregate direkapitulasi berdasarkan persentase luas kerusakan untuk memudahkan penilaian pengaruh kerusakan perkerasan terhadap indek perkerasan dari yang paling besar sampai dengan yang paling kecil berdasarkan Pavement Condition Index (PCI). Pada Tabel 4.7. diperlihatkan tingkat kerusakan perkerasan berat dengan empat jenis kerusakan perkerasan.

Tabel 4.7. Hasil Pemeriksaan Berdasarkan Persentase Luas Kerusakan dan Urutan Nilai PCI

\begin{tabular}{|c|l|c|c|c|c|c|c|}
\hline \multirow{2}{*}{ No } & \multirow{2}{*}{$\begin{array}{c}\text { Jenis Kerusakan } \\
\text { Perkerasan }\end{array}$} & \multicolumn{6}{|c|}{ Luas Kerusakan (tingkatan berat) } \\
\cline { 3 - 8 } & & \multicolumn{3}{|c|}{$30 \%$} & \multicolumn{2}{|c|}{$60 \%$} & \multicolumn{2}{|c|}{$90 \%$} \\
\cline { 3 - 8 } & PCI & Rate & PCI & Rate & PCI & Rate \\
\hline 1 & Polished Aggregate & 99 & excellent & 98 & excellent & 97 & excellent \\
\hline 2 & Bleeding & 98 & excellent & 96 & excellent & 94 & excellent \\
\hline 3 & Disintegration & \multicolumn{7}{|c|}{} \\
\hline & - stripping & 91 & excellent & 89 & excellent & 85 & excellent \\
\hline & - ravelling & 91 & excellent & 89 & excellent & 85 & excellent \\
\hline & - potholes & 85 & excellent & 78 & very good & 75 & very good \\
\hline 4 & Utility Cut Depression & 84 & very good & 83 & very good & 82 & very good \\
\hline
\end{tabular}

\subsection{Pembahasan}

Pengaruh cacat permukaan (disintegration) yang berupa pengelupasan lapisan permukaan (stripping), pelepasan butir (ravelling), lubang (potholes) pada perkerasan lentur adalah turunnya indek permukaan. Stripping dengan tingkat kerusakan adalah berat dan luas kerusakan perkerasan jalan mencapai 30\%, 60\%, dan 90\% nilai Pavement Condition Index (PCI) masih tinggi berkisar 85 sampai dengan 91. Hal ini menunjukkan bahwa stripping tidak mempengaruhi pelayanan perkerasan jalan, karena kategori perkerasan jalan masih sempurna (excellent). Tetapi jika pengelupasan lapisan permukaan ini tidak dirawat secara baik, secara perlahan-lahan akan mengakibatkan terjadinya lubang-lubang pada permukaan perkerasan jalan yang dapat mengakibatkan turunnya pelayanan lebih cepat.

Ravelling atau pelepasan butir pengaruhnya terhadap pelayanan perkerasan jalan adalah sama seperti dengan stripping. Tingkat kerusakan perkerasan jalan $30 \%$, 60\%, dan 90\% nilai PCI masih tinggi berkisar 85 sampai dengan 91. Hal ini disebabkan jenis kerusakannya hampir sama sehingga pengaruhnya juga sama terhadap perkerasan jalan. Stripping dan ravelling terjadi akibat permukaan perkerasan yang secara terus menerus bersentuhan dengan ban kendaraan sehingga lama kelamaan terjadi pelepasan butir dan perkerasan menjadi aus. Proses kimiawi berupa hilangnya aspal akibat oksidasi mengakibatkan ikatan 
aspal dengan agregat menjadi lemah dan lama kelamaan mengakibatkan butirbutir agregat saling terlepas.

Potholes atau lubang-lubang yang terdapat pada perkerasan jalan sebesar $30 \%$, 60\%, dan $90 \%$ dari luas perkerasan jalan dengan tingkatan kerusakan berat mengakibatkan nilai Pavement Condition Index (PCI) turun menjadi 75 sampai dengan 85. Penurunan nilai PCI sampai dengan 25\% dari awal konstruksi karena lubang-lubang yang ada pada perkerasan jalan mencapai $90 \%$ dari total luas perkerasan jalan sudah harus dilakukan perbaikan secara menyeluruh atau overlay. Lubang-lubang ini jika dibiarkan terus dengan cepat akan mengakibatkan perkerasan jalan sulit untuk dilintasi oleh kendaraan dan membahayakan pengendara. Cacat permukaan yang berupa potholes adalah jenis kerusakan yang sangat besar pengaruhnya terhadap pelayanan jalan. Kerusakan perkerasan jalan akibat dari tidak adanya tanggungjawab pelaksana yang melakukan galian dan timbunan kembali pada sisi-sisi perkerasan disebut dengan penurunan pada bekas penanaman utilitas (utility cut depression). Sering dijumpai sepanjang tepi perkerasan digali untuk pekerjaan utilitas berupa galian untuk penanaman kabel listrik ataupun kabel telepon, galian untuk pipa air, galian untuk drainase dan lain sebagainnya. Pada waktu dilakukan penanaman kembali tidak dilakukan sebagaimana mestinya untuk mencapai kepadatan yang disyaratkan, sehingga perkerasan jalan disepanjang tepinya menjadi retakan-retakan atau pecah-pecah yang lama kelamaan terlepas dari perkerasan. Utility cut depression mengakibatkan penurunan nilai PCI menjadi 82 sampai dengan 84 yang secara rating masih dikategorikan perkerasan sempurna (excellent). Tetapi akibat dari tidak kuatnya sisi perkerasan sepanjang perkerasan jalan mengakibatkan penurunan konstruksi jalan yang mengakibatkan lapisan permukaan menjadi rusak berupa retakan-retakan, kemudian akibat dari pengaruh cuaca dan beban kendaraan mengakibatkan aspal menjadi pecah-pecah yang dengan cepat mengakibatkan terjadinya lubang-lubang di sepanjang perkerasan jalan atau perkerasan aspal hilang menjadi bongkahan-bongkahan yang kecil dan lama kelamaan akibat dari lintasan ban kendaraan terhempas jauh dari badan jalan. Utility cut depression dapat dikurangi dampaknya jika adanya koordinasi pekerjaan dengan pihak-pihak yang bertanggungjawab terhadap perawatan perkerasan jalan, dimana pada saat pelaksanaan pekerjaan utilitas galian disepanjang perkerasan dilakukan secara hati-hati dan sejauh mungkin dari perkerasan jalan. Timbunan kembali harus dilakukan lapis-demi lapis untuk mendapatkan kepadatan yang disyaratakan, atau dapat menggunakan bahan tambah untuk meningkatkan kepadatan dan kekuatan tanah disepanjang perkerasan jalan yang sudah digali sebelumnya.

Penggunaan persentase aspal dalam campuran aspal yang melebihan batas optimum dapat mengakibatkan terjadinya bleeding pada perkerasan jalan. Bleeding adalah terbenamnya agregat dalam aspal disebabkan terlalu banyaknya persentase aspal, hal ini menyebabkan jalan menjadi licin dan sangat licin pada waktu hujan turun yang sangat berpotensi terjadinya slip pada roda kendaraan yang membahayakan pengemudi dan pada siang hari perkerasan menjadi silau akibat pantulan sinar matahari. Bleeding mengakibatkan penurunan nilai PCI menjadi 94 sampai dengan 98 yang secara rating masih dikategorikan perkerasan sempurna (excellent). Tetapi akibat dari terlalu banyaknya kadar aspal pada 
campuran mengakibatkan potensi terjadinya alur menjadi sangat besar. Lintasan roda kendaraan dengan beban yang besar pada bagian perkerasan jalan yang bleeding lama kelamaan akan mengakibatkan terjadinya alur. Bila sudah terjadi alur, maka umur pelayanan jalan akan turun secara signifikan dan mengurangi kenyamanan berlalulintas dan akan membuka peluang terjadinya kerusakankerusakan yang lain. Terjadinya bleeding pada perkerasan lentur dapat hindari dengan penerapan kadar aspal adalah kadar aspal minimum dari ring kadar aspal optimum yang disyaratakan untuk suatu jenis campuran aspal. Pemahaman semakin banyak aspal perkerasan menjadi semakin awet harus dihilangkan, tetapi kadar aspal disesuaikan dengan jenis perkerasan yang akan dipakai. Ronggarongga dalam campuran harus disiapkan sesuai dengan yang disyaratakan, sehingga aspal yang mencair pada temperatur tinggi dapat mengisi rongga-rongga tersebut dan tidak muncul dipermukaan dan membenamkan agregat. Aspal pada perkerasan jalan yang berfungsi sebagai bahan pengikat agregat lama kelamaan akan menipis, hal ini disebabkan oleh proses oksidasi dan gesekan permukaan ban kendaraan dengan lapisan permukaan perkerasan jalan. Aspal bila dibiarkan langsung berhubungan dengan udara luar akan terjadi proses oksidasi (bereaksinya aspal dengan udara), dimana pada proses oksidasi ini akan terbentuk lapisan tipis pada bagian atasnya dan lapisan ini akan melindungi aspal dibawahnya sehingga oksidasi hanya terbatas pada lapisan paling atas saja. Bila lapisan ini pecah maka akan muncul aspal cair lagi dan akan terjadi oksidasi demiki-an seterusnya. Lapisan tipis yang terbentuk (hasil oksidasi) timbul komponen baru yang dapat larut dalam air dan akan hilang terbawa air pada waktu hujan. Inilah yang menyebabkan kadar aspal pada perkerasan lentur lama kelamaan akan berkurang. Selama perkerasan jalan digunakan untuk melayani lalulintas maka selama itu akan selalu berhubungan dengan lingkungan luar, sehingga dapat dipastikan bahwa lapisan keras tersebut tidak dapat terhindar dari proses oksidasi. Upaya yang paling dapat dilakukan untuk mengurangi oksidasi terasebut adalah dengan membuat campuran yang rapat dengan melakukan pemadatan yang optimal agar udara dan air tidak dapat masuk kedalam perkerasan sehingga dihapkan oksidasi hanya terjadi pada permukaan saja dan membuat serta memelihara sistem drainase dengan baik sehingga diharapkan dapat memperlambat proses pelarutan dari komponen aspal baru yang terbentuk akibat oksidasi.

Indek permukaan perkerasan jalan yang ditentukan berdasarkan metode PCI untuk jenis kerusakan potholes, utility cut depression, stripping, ravelling, bleeding dan polished aggregate menunjukkan perkerasan jalan masih dalam kategori sempurna dan sangat baik. Tetapi tidak berarti dengan jenis kerusakan tersebut perkerasan jalan tidak perlu perbaikan atau perawatan. Nilai PCI menunjukkan kondisi pelayanan jalan pada saat itu dan tanpa adanya perbaikan serta perawatan terhadap kerusakan-kerusakan tersebut akan mengakibatkan pelayanan jalan turun lebih cepatatau mengakibatkan kerusakan-kerusakan lain yang lebih berat. Berdasarkan jenis kerusakannya potholes dengan nilai PCI tersisa 75 merupakan jenis kerusakan yang paling besar pengaruhnya terhadap pelayanan perkerasan jalan, diikuti dengan utility cut depression dengan nilai PCI tersisa adalah 82, kemudian stripping dan ravelling dengan nilai PCI tersisa adalah 
85, bleeding dengan nilai PCI tersisa 94 dan terakhir adalah polished aggregate dengan nilai PCI tersisa sebesar 97.

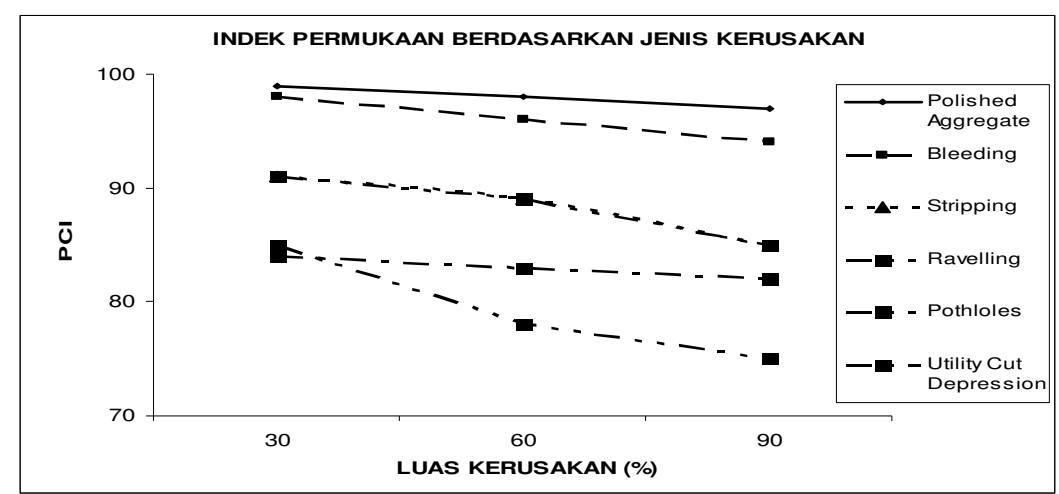

\section{Gambar 4.1 Indek Permukaan Berdasarkan Jenis Kerusakan}

Gambar 4.1. menunjukkan potholes dengan tingkat kerusakan berat dan luas kerusakan $30 \%$ nilai PCI sebesar 85 masih lebih baik daripada utility cut depression dengan nilai PCI 84 tetapi dengan luas kerusakan $60 \%$ dan $90 \%$ nilai PCI turun sangat signifikan dan perkerasan jalan sudah dikategorikan sangat baik bukan sempurna. Nilai PCI dari kerusakan stripping dan ravelling adalah sama dan pada luas kerusakan $90 \%$ nilai PCI turun menjadi 85. Polished aggregate dan bleeding dengan luas kerusakan 30\%, 60\% dan 90\% tidak turun secara signifikan tetapi masih dalam kategori sempurna.

\section{Kesimpulan}

Dari hasil penelitian dan pembahasan dapat diambil beberapa kesimpulan sebagai berikut:

1. Polished aggregate dan bleeding dengan tingkat kerusakan berat dan luas kerusakan sampai dengan $90 \%$ dari total perkerasan jalan nilai PCI masih lebih besar dari 90 dan secara rating perkerasan jalan masih dikategorikan sempurna.

2. Stripping dan ravelling mempunyai nilai PCI yang sama dengan tingkat kerusakan berat serta luas kerusakan mencapai $90 \%$ dari total perkerasan jalan nilai PCI masih lebih besar dari 85 dan secara rating perkerasan jalan masih dikategorikan sempurna.

3. Potholes dan utility cut depression dengan tingkat kerusakan berat dan luas kerusakan sampai dengan $90 \%$ dari total perkerasan jalan nilai PCI dibawah 85 dan secara rating perkerasan jalan masih dikategorikan sangat baik.

4. Potholes mempunyai pengaruh paling besar terhadap pelayanan perkerasan jalan karena nilai PCI tersisa adalah 75.

5. Polished aggregate mempunyai pengaruh paling kecil terhadap pelayanan perkerasan jalan karena nilai PCI tersisa masih 97.

Untuk penyempurnaan penelitian ini agar nantinya dapat melengkapi hasil yang lebih komprehensip maka dapat diberikan rekomendasi sebagai berikut:

1. Penelitian terhadap utility cut depression perlu dilakukan secara lebih dalam dan seksama untuk melihat pengaruhnya terhadap tanah dasar dan lapisan pondasi. 
2. Adanya penelitian tentang besaran potholes dan pengaruhnya terhadap percepatan kerusakan konstruksi jalan.

3. Perlunya penelitian hubungan antara bleeding dan alur pada konstruksi jalan dengan lalulintas tinggi dan berat

\section{Daftar Kepustakaan}

1. Asphalt Institute, 2001, Introduction to Asphalt, Manual Series No.5, Eighth Edition,USA.

2. Departement of Transportation, 1982, Guidelines and Procedures for Maintenance of Airport Pavement, USA

3. Fithra, 2009, Penurunan Indek Permukaan Jalan pada Perkerasan Lentur Akibat Retakan Berdasarkan Metode Pavement Condition Index, Jurnal Saintek, Volume 7 Nomor 1, Fakultas Teknik, Penerbit Universitas Malikussaleh, Lhokseumawe.

4. Hardiyatmo, H. C., 2009, Pemeliharaan Jalan Raya, Edisi kedua, Penerbit Gadjah Mada University Press, Yogyakarta.

5. Shahim, M.Y., 1994, Pavement Management for Airport, Road, and Parking Lots, Chapman \& Hall, New York.

6. Suwandi, et.all., 2008, Evaluasi Tingkat Kerusakan Jalan dengan Metode Pavement Condition Index (PCI) untuk Menunjang Pengambilan Keputusan, Jurnal Forum Teknik Sipil, Nomor XVIII/3, Penerbit Universitas Gadjah Mada, Yogyakarta. 